Old Dominion University

ODU Digital Commons

Community \& Environmental Health Faculty

Publications

Community \& Environmental Health

$7-1-2020$

\title{
Predictors of Biologic Use and Satisfaction Among Patients With Psoriasis: An Analysis and Geographic Visualization of the 2016 and 2017 National Psoriasis Foundation Annual Surveys
}

\author{
Clinton W. Enos \\ Hadiza I. Galadima \\ Old Dominion University, hgaladim@odu.edu \\ Arjun Saini \\ Stacie Bell \\ Michael Siegel \\ Pediatric Dermatology Research Alliance
}

See next page for additional authors

Follow this and additional works at: https://digitalcommons.odu.edu/commhealth_fac_pubs

Part of the Clinical Epidemiology Commons, Dermatology Commons, Medical Education Commons, and the Skin and Connective Tissue Diseases Commons

\section{Original Publication Citation}

Enos, C. W., Galadima, H., Saini, A. D., Bell, S., Siegel, M., \& Van Voorhees, A. S. (2020). Predictors of biologic use and satisfaction among patients with psoriasis: An analysis and geographic visualization of the 2016 and 2017 National Psoriasis Foundation annual surveys. Journal of Psoriasis and Psoriatic Arthritis, 5(3), 100-108. https://doi.org/10.1177/2475530320925553

This Article is brought to you for free and open access by the Community \& Environmental Health at ODU Digital Commons. It has been accepted for inclusion in Community \& Environmental Health Faculty Publications by an authorized administrator of ODU Digital Commons. For more information, please contact digitalcommons@odu.edu. 


\section{Authors}

Clinton W. Enos, Hadiza I. Galadima, Arjun Saini, Stacie Bell, Michael Siegel, and Abby S. Van Voorhees 


\title{
Predictors of Biologic Use and Satisfaction Among Patients With Psoriasis: An Analysis and Geographic Visualization of the 2016 and 20 I 7 National Psoriasis Foundation Annual Surveys
}

Journal of Psoriasis and Psoriatic Arthritis 2020, Vol. 5(3) 100-108

(c) The Author(s) 2020

Article reuse guidelines: sagepub.com/journals-permissions DOI: $10.1177 / 2475530320925553$ journals.sagepub.com/home/jps

@SAGE

\author{
Clinton W. Enos, MD' ${ }^{\circledR}$, Hadiza Galadima, PhD $^{2}$, \\ Arjun D. Saini, $\mathrm{MD}^{3} \mathbb{D}$, Stacie Bell, $\mathrm{PhD}^{4}$, Michael Siegel, $\mathrm{PhD}^{5}$, \\ and Abby S. Van Voorhees, MD'
}

\begin{abstract}
Background: There are an increasing number of biologic therapies approved for the treatment of psoriasis. Previous reports have identified undertreatment as a concern in the United States. Undertreatment has been associated with decreased patient satisfaction and increased morbidity. Objectives: Assess biologic use and satisfaction among respondents to the 2016 and 2017 National Psoriasis Foundation (NPF) Annual Surveys. Methods: Retrospective data analysis of the 2016 and 2017 NPF Annual Survey responses from individuals with psoriasis. ArcGIS Pro software was utilized to generate maps and perform an optimized hot spot analysis of moderate-to-severe psoriasis and biologic use. Results: There were 427 patients with psoriasis involving the skin alone. Biologics were used in $<23 \%$ of respondents, while nearly $69 \%$ reported body surface area (BSA) $>3 \%$. Respondents with BSA $<3 \%$ and $3 \%$ to $4 \%$ were less likely to be on biologic therapy (odds ratio [OR]: 0.29, 0.1 I-0.78 and OR: 0.22, 0.09-0.56, respectively). Nonbiologic users were more likely to be very unsatisfied with their treatment compared to those receiving biologic therapy (OR: 5.23, 2.80-9.75). With geographic information systems (GIS), counties with increased moderate-to-severe disease were identified in the southeastern United States. Conclusion: Despite the increasing number of Food and Drug Administration-approved biologic medications, the proportion of respondents on biologic therapy remained small. Treatment with biologics correlated with less residual disease and increased satisfaction. Geographic variation in state legislation as well as state and federal health insurance did not impact biologic use. However, using GIS, we identify a greater burden of moderate-tosevere disease among respondents in the Southeastern United States and a lack of commensurate use of biologics in those areas.
\end{abstract}

\section{Keywords}

psoriasis, geography, biologic treatment, patient satisfaction, geographic information systems, National Psoriasis Foundation, NPF

\section{Background}

Psoriasis is a chronic, immune-mediated, inflammatory disease affecting roughly $3 \%$ of the US population. ${ }^{1}$ Traditionally, psoriasis has been described as a disease of the skin and joints; however, it is now understood to have a systemic impact. Subsequently, treating to the target of a body surface area (BSA) $\leq 1 \%$ within 3 months of starting therapy has been proposed as a primary focus. ${ }^{2}$

The past decade has brought multiple additions to the armamentarium for psoriatic disease. Among these, the biologics have revolutionized both our understanding of psoriasis and the potential for achieving treatment goals in moderate-to-
' Department of Dermatology, Eastern Virginia Medical School, Norfolk, VA, USA

${ }^{2}$ School of Community and Environmental Health, College of Health Sciences-Old Dominion University, Norfolk, VA, USA

${ }^{3}$ Eastern Virginia Medical School, Norfolk, VA, USA

${ }^{4}$ National Psoriasis Foundation, Portland, OR, USA

${ }^{5}$ Pediatric Dermatology Research Alliance, Indianapolis, IN, USA

\section{Corresponding Author:}

Clinton W. Enos, MD, Eastern Virginia Medical School, Department of Dermatology, 72I Fairfax Ave, Ste 200, Norfolk, VA 23507, USA.

Email: enoscw@evms.edu 
severe psoriasis; further, their benefit-to-risk profile has been very positive. ${ }^{3}$ At time of writing, there are 12 Food and Drug Administration-approved biologic therapies (not including biosimilars) for the treatment of psoriatic disease. Despite this, undertreatment and dissatisfaction with treatment are significant problems in the United States. ${ }^{4}$

The National Psoriasis Foundation (NPF) conducts an annual survey that targets a patient population with moderate-to-severe disease and collects data on self-reported BSA, treatment history, demographic information, as well as satisfaction. Here we (1) characterize the respondent population of the 2016 and 2017 NPF Annual Surveys stratified by treatment with biologics, (2) assess treatment satisfaction among individuals with psoriasis, and (3) use geographic information systems (GIS) to analyze potential spatial differences in biologic use. We hypothesized that (1) a majority of respondents would be treated with biologics, (2) respondents receiving biologic therapy would be more satisfied with their treatment, and (3) the use of biologics is impacted by geographic differences in state legislation as well as federal and state health insurance expansion.

\section{Methods and Design}

The study was approved by the Eastern Virginia Medical School institutional review board (18-03-NH-0069-EVMS). The NPF collects data as part of an annual survey conducted via email and telephone. The 2016 and 2017 annual surveys were used in this analysis. The survey asks respondents to selfreport severity using BSA where one hand is equivalent to $1 \%$ BSA. Data are also collected on demographics, treatment(s) used, satisfaction with treatment, impact on daily life, specialty of provider caring for their psoriatic disease, barriers to treatment, and comorbidities. Respondents identifying as having psoriatic arthritis were excluded from the analysis. Treatments were categorized as biologic or nonbiologic. Biologic treatments listed in the 2016 and 2017 surveys included etanercept, infliximab, adalimumab, golimumab, certolizumab, ustekinumab, secukinumab, ixekinumab, brodalumab, guselkumab, and infliximab-dyyb. Nonbiologic treatments included cyclosporine, methotrexate, acitretin, apremilast, ultraviolet B phototherapy, excimer, pulse dye laser, nonsteroidal topical medications, and topical steroids.

Satisfaction was a primary outcome measure. The survey included a question on satisfaction with treatment, and each response was measured on a scale of 10 ranging from very unsatisfied (1) to very satisfied (10). The response variable was regrouped into 4 categories to allow for larger numbers in each and create a new ordinally scaled response variable to measure satisfaction such that $1=$ very unsatisfied, between 2 and $5=$ unsatisfied, between 6 and $9=$ satisfied, and $10=$ very satisfied.

The primary independent variables included a binary variable representing whether a patient received biologic therapy ("biologic"), and a current disease severity variable recorded on 6 scales $(1=$ "no or very little psoriasis," $2=$ " $<3 \%$ BSA,"
$3=" 3 \%$ to $4 \%$ BSA," $4=$ " $5 \%$ to $10 \%$ BSA," $5=" 11 \%$ to $20 \%$ BSA," and $6=">20 \%$ BSA"). We also evaluated demographic covariates that included age, sex, race/ethnicity, household income, insurance provider, and total number of comorbidities. A quality of life variable measuring psoriasis impact was also included; this information is collected on a scale of 1 to 10 (10 being a "very large problem" and 1 being "no problem at all") and was considered a continuous variable for the analysis.

Geographic variables chosen for the analysis included: residence in a Medicaid expansion state, residence in a state with Step therapy legislation, residence within 50 or 100 miles of an active NPF medical board member. States with Medicaid expansion at time of writing are Alaska, Arkansas, Arizona, California, Colorado, Connecticut, District of Columbia, Delaware, Hawaii, Iowa, Idaho, Illinois, Indiana, Kentucky, Louisiana, Massachusetts, Maryland, Maine, Michigan, Minnesota, North Dakota, Nebraska, North Hampshire, New Jersey, New Mexico, Nevada, New York, Ohio, Oregon, Pennsylvania, Utah, Virginia, Vermont, Washington, and West Virginia. ${ }^{5}$ States with Step therapy legislation enacted at time of writing are Oregon, California, New Mexico, Texas, Kansas, Missouri, Arkansas, Louisiana, Mississippi, Illinois, Kentucky, Indiana, West Virginia, and New York. ${ }^{6}$ Geographic region (census division and census region) was also considered a covariate of interest to see if the correlation between satisfaction, biologics use, and disease severity is different according to the geographic location.

\section{Statistical Analysis}

Baseline demographics, clinical, and geographic characteristics were summarized and compared between those who used biologics and those who did not in a bivariate analysis using the $\chi^{2}$ test for categorical variables and the Student $t$ test for continuous variables. A multivariable logistic regression adjusting for age, sex, ethnicity, income, insurance, the geographic variables, and the provider specialty was used to model the odds of biologics use. Adjusted odds ratios with their $95 \%$ confidence intervals (CIs) were reported.

Analysis of variance, Chi-square, and Fisher exact tests were used in a univariate analysis to compare baseline clinical and demographic patient characteristics by satisfaction category. A cumulative logit model was used to investigate the effects of biologic therapy and disease severity on satisfaction while adjusting for the significant covariates found in the univariate analysis. The model also included an interaction term between biologic and disease severity to examine the potential differences of biologic use within each level of severe psoriasis. Bonferroni method for multiple comparisons was used to identify significant differences. The model yielded adjusted odds ratios with their $95 \%$ CIs. All analyses were performed using SAS version 9.4 (SAS Institute) and the statistical significance level was set at $\alpha=.05$. 
Table I. Descriptive Statistics by Biologics Use.

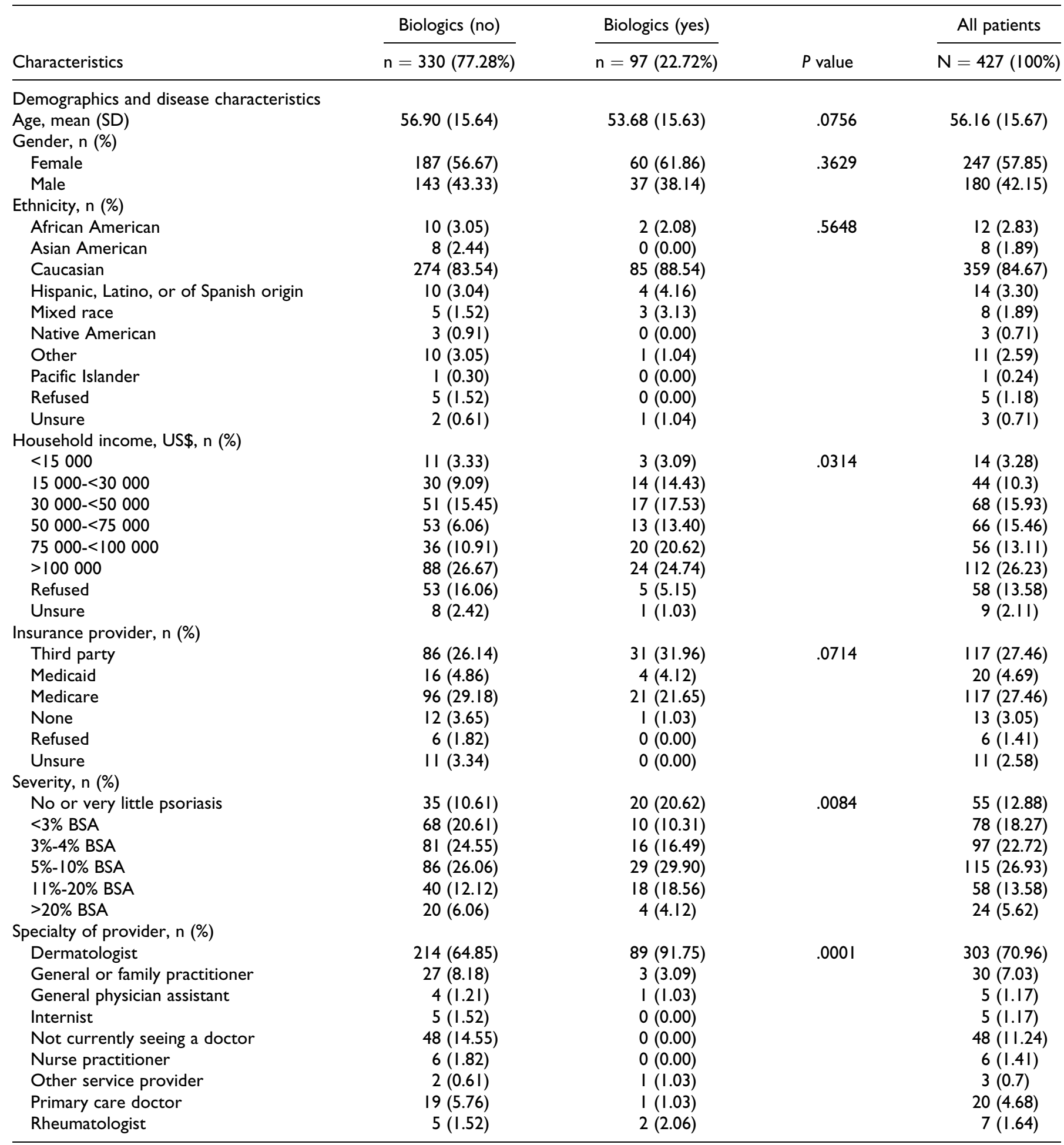

Abbreviations: BSA, body surface area; SD, standard deviation.

\section{Map Generation}

ArcGIS Pro (Esri) was used to generate maps by linking survey responses to zip codes. Responses were summarized into counties. The optimized Hot Spot analysis tool was used to identify counties with significant clustering of respondents with moderate-to-severe psoriasis and biologic use among moderate-to-severe psoriasis; counts normalized to million population per county were used for the hot spot analysis. 
Table 2. Predictors of Biologic Use Among Respondents of the 2016 and 2017 National Psoriasis Foundation Annual Survey.

\begin{tabular}{lrrr}
\hline & $\begin{array}{c}95 \% \\
\text { Odds ratio } \\
\text { estimate }\end{array}$ & $\begin{array}{c}\text { confidence } \\
\text { limits }\end{array}$ \\
\hline $\begin{array}{l}\text { Specialty of provider (reference: } \\
\text { dermatologist) }\end{array}$ & $P=.001$ \\
$\quad$ Family/nurse practitioner or general & 0.08 & 0.01 & 0.50 \\
General physician assistant/doctor of & 0.28 & 0.04 & 1.97 \\
$\quad$ internal medicine & & & \\
Not currently seeing a doctor or other & 0.07 & 0.02 & 0.36 \\
Primary care doctor & 0.17 & 0.03 & 0.92 \\
Rheumatologist & 0.75 & 0.11 & 5.25 \\
Severity (reference: no or very little & $P=.0233$ & \\
Psoriasis) & & & \\
<3\% BSA & 0.29 & 0.11 & 0.78 \\
3\%-4\% BSA & 0.22 & 0.09 & 0.56 \\
5\%-I0\% BSA & 0.49 & 0.21 & 1.14 \\
II\%-20\% BSA & 0.65 & 0.24 & 1.79 \\
$>20 \%$ BSA & 0.46 & 0.11 & 1.88 \\
\hline
\end{tabular}

Abbreviation: BSA, body surface area.

\section{Results}

\section{Respondent Characteristics}

There were a combined 826 respondents to the 2016 and 2017 NPF Annual Surveys; of these, 427 did not report joint disease and were included in the study (Table 1). The average age was 56.1 (standard deviation $[\mathrm{SD}]=15.6)$ years and about $84 \%(\mathrm{n}=$ $359)$ identified as Caucasian. The majority of respondents were female $(57.8 \%, \mathrm{n}=247)$ and about $26 \%(\mathrm{n}=112)$ had an income of more than US\$100 000. Roughly, $27 \%(n=117)$ utilized private insurance from a third party; a similar proportion used Medicare $(27 \%, \mathrm{n}=117)$; Medicaid was used in $<5 \%$; and around $3 \%$ of respondents lacked health insurance. Nearly $69 \%$ of respondents reported BSA $>3 \%$, with the greatest proportion being BSA $5 \%$ to $10 \%(26.9 \%, \mathrm{n}=115)$. The majority of respondents were managed by a dermatologist $(71 \%, \mathrm{n}=$ $303)$; and there was no significant evidence of association between disease severity and specialty of provider $(P=.387)$.

\section{Biologic Use Among Respondents}

Less than one-quarter of respondents $(22.7 \%, \mathrm{n}=97)$ were treated with biologics (Table 1). Of those receiving biologics, the most frequent responses included income more than US\$100 $000(\mathrm{n}=24,24.7 \%)$, use of a third-party medical insurance $(\mathrm{n}=31,31.9 \%)$, managed by a dermatologist $(\mathrm{n}=$ $81,91.7 \%)$, and BSA of $5 \%$ to $10 \%(\mathrm{n}=29,29.9 \%$; Table 1$)$. In the univariate analysis, income level (US\$15 000-US\$100 $000)$ favored use of biologics $(P=.031)$; however, this relationship was lost in the multivariate analysis. For each level of disease severity, respondents more frequently reported not being on a biologic $(P=.008$; Supplementary Table 1$)$. In the multivariate analysis, patients with BSA $<3 \%$ and BSA $3 \%$ to
$4 \%$ had a lower odds of being on biologic therapy compared to those responding as having "no or very little psoriasis" $(71 \%$ and $78 \%$ lower odds, $95 \% \mathrm{CI}, 0.11-0.78$ and $95 \% \mathrm{CI}, 0.09-0.56$, respectively; Table 2). Respondents managed by a dermatologist were more frequently treated with biologics $(91.7 \%$ vs $64.8 \%, P=.0001$; Table 1$)$. When respondents were managed by a provider other than a dermatologist, they were less likely to be on a biologic: for example, there was roughly a $92 \%$ lower likelihood of being on a biologic if managed by a nurse practitioner (95\% CI, 0.01-0.50) and $83 \%$ lower if managed by a primary care doctor (95\% CI, 0.03-0.92; Table 2).

\section{Patient Satisfaction Is Greater When Biologics Are Used in the Treatment of Psoriasis}

Of the 427 respondents, 22 were missing satisfaction survey responses and excluded from the analyses. Overall, the majority of respondents reported being either "satisfied" $(\mathrm{n}=199$, $49.1 \%)$ or "unsatisfied" ( $\mathrm{n}=109,26.9 \%)$ with treatment; the least $(\mathrm{n}=23,5.6 \%)$ reported being "very unsatisfied" and $\mathrm{n}=$ $74(18.2 \%)$ were "very satisfied" with treatment (Table 3 ). Among patients on biologic $(\mathrm{n}=94)$, about $87 \%(\mathrm{n}=82)$ reported being either satisfied or very satisfied with treatment versus roughly $13 \%(\mathrm{n}=12)$ with lesser satisfaction $(P<$ .0001). Respondents "very satisfied" with treatment more often had little to no psoriasis ( $\mathrm{n}=22,29.7 \%$ ), utilized private (third party) insurance $(\mathrm{n}=39,52.7 \%)$, reported $>$ US $\$ 100000$ annual income $(\mathrm{n}=20,27 \%)$, and reported one comorbid disease $(n=20,27.0 \%)$. Very satisfied respondents also reported a lower mean impact on quality of life (3.58) compared to all other levels of satisfaction $(P=.0178)$. Whereas respondents "very unsatisfied" with treatment more often had BSA $3 \%$ to $4 \%(n=6,26 \%)$, utilized Medicare $(n=12$; $52.1 \%$ ), reported annual income US\$30 000 to US\$50 000 (n $=8,34.7 \%)$, and reported no comorbid disease $(\mathrm{n}=8,34.7 \%)$. Very unsatisfied respondents reported the greatest impact on quality of life (6.32; Table 3).

After adjusting for household income, insurance status, total comorbidities, disease severity, biologic use, and psoriasis impact on quality of life, predictors of being very unsatisfied were determined (Table 4). Nonbiologic users were roughly 5 times more likely to be very unsatisfied with their treatment compared to those receiving biologic (95\% CI, 2.80-9.75). Respondents with BSA ranging 3\% to $20 \%$ were roughly 2 to 5 times more likely to be very unsatisfied with their treatment, when compared to having no or very little psoriasis $(P=$ .0008). At all levels of severity, there was a greater probability of being unsatisfied or very unsatisfied when not treated with a biologic compared to those treated with a biologic $(P=.0401$; Figure 1). Compared to those with a private insurance, Medicare recipients were 1.75 times more likely to be very unsatisfied with their treatment (95\% CI, 1.06-2.88); the uninsured were 5 times more likely to be very unsatisfied with treatment (95\% CI, 1.74-19.4). Lastly, patients reporting greater impact on quality of life were 1.18 times more likely to be very unsatisfied with treatment (95\% CI, 1.09-1.27). 
Table 3. Descriptive Statistics for Demographic and Clinical Characteristics by Satisfaction.

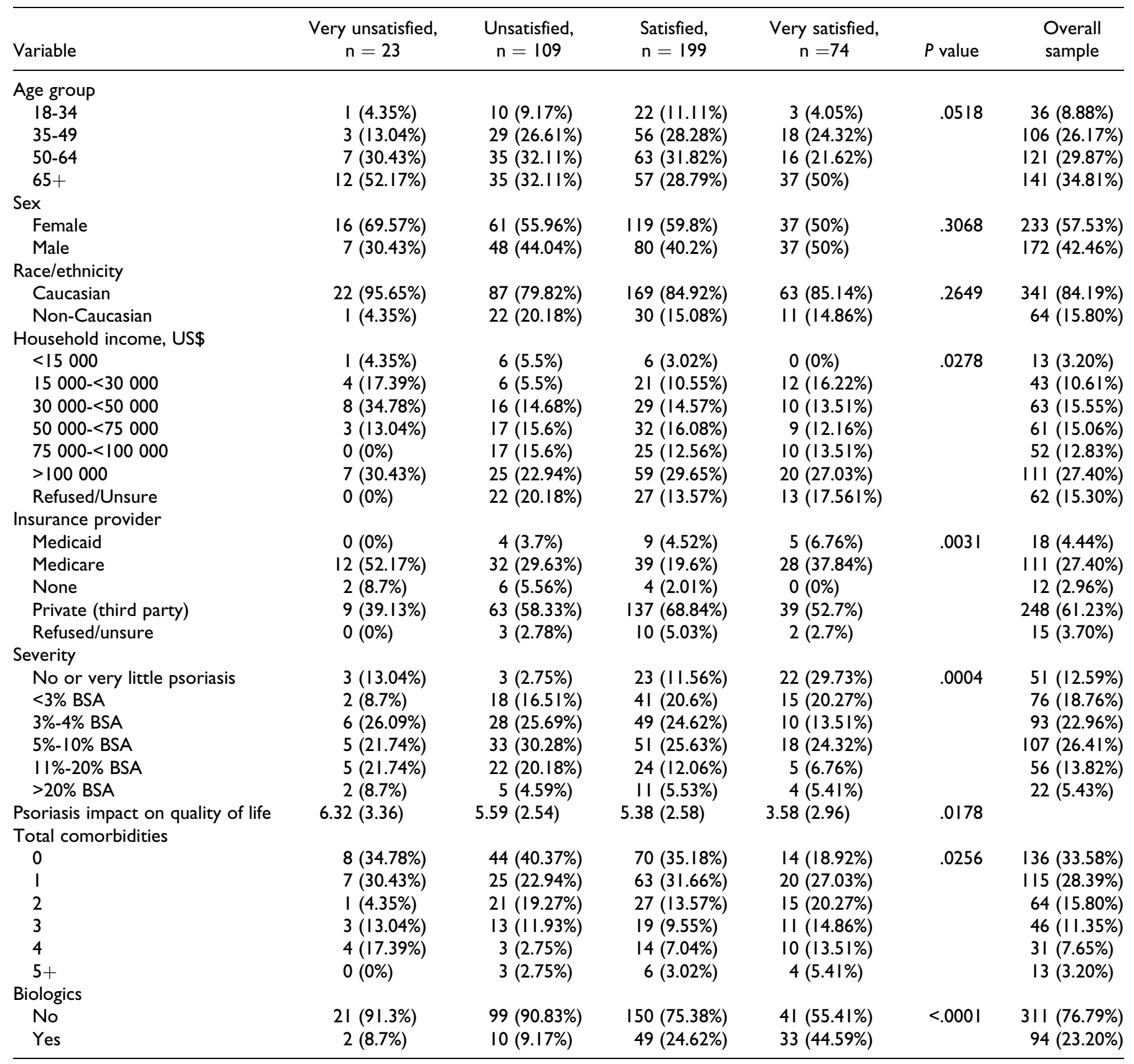

Abbreviation: BSA, body surface area.

\section{Geographic Variables and Biologic Use}

Next we sought to understand if geographic variations in legislation (Step therapy legislation), health insurance (Medicaid expansion), or proximity to a psoriasis thought leader might impact biologic use among survey respondents (Supplemental Table 2). Neither Medicaid expansion nor Step therapy legislation was associated with biologic use. Biologics were more frequently used when respondents resided within 100 miles of an NPF medical board member $(P=.0161)$; however, this relationship was lost in the multivariate analysis (data not shown). There was also no evidence that satisfaction with treatment varied regionally $(P=.0687$ for US census division and $P$ $=.138$ for US census region, data not shown).

\section{Geographic Clustering of Moderate-to-Severe Psoriasis and Biologic Use}

Using GIS software, respondents were mapped by county to show the spatial distribution of moderate-to-severe psoriasis and biologic use (Figure 2A). An optimized hot spot analysis 
Table 4. Adjusted Odds Ratio of Being Very Unsatisfied With Treatment.

\begin{tabular}{|c|c|c|}
\hline Variable & Odds ratio estimate $(95 \% \mathrm{Cl})$ & $P$ value \\
\hline \multicolumn{3}{|l|}{ Biologics } \\
\hline Yes & Reference & \multirow[t]{2}{*}{$<.0001$} \\
\hline No & $5.23(2.805-9.75 I)$ & \\
\hline \multicolumn{3}{|l|}{ Severity } \\
\hline No or very little psoriasis & Reference & \multirow[t]{6}{*}{.0008} \\
\hline$<3 \%$ BSA & I.667 (0.688-4.036) & \\
\hline $3 \%-4 \%$ BSA & $3.534(1.57-7.954)$ & \\
\hline $5 \%-10 \%$ BSA & $2.75 \mathrm{I}(\mathrm{I} .32 \mathrm{I}-5.732)$ & \\
\hline II\%-20\% BSA & $5.334(2.296-12.39)$ & \\
\hline$>20 \%$ BSA & $0.862(0.215-3.457)$ & \\
\hline \multicolumn{3}{|l|}{ Household income, US\$ } \\
\hline$<15000$ & Reference & \multirow[t]{7}{*}{.0542} \\
\hline $15000-<30000$ & $0.252(0.073-0.872)$ & \\
\hline $30000-<50000$ & $0.856(0.264-2.779)$ & \\
\hline $50000-<75000$ & $0.589(0.179-1.933)$ & \\
\hline $75000-<100000$ & $0.641(0.192-2.139)$ & \\
\hline$>100000$ & $0.649(0.206-2.041)$ & \\
\hline Refused/unsure & $0.589(0.177-1.964)$ & \\
\hline \multicolumn{3}{|l|}{ Insurance provider } \\
\hline Private (third party) & Reference & \multirow[t]{5}{*}{.0058} \\
\hline Medicaid & $0.566(0.208-1.542)$ & \\
\hline Medicare & $1.75(1.062-2.884)$ & \\
\hline None & $5.836(1.749-19.466)$ & \\
\hline Refused/unsure & $0.929(0.312-2.766)$ & \\
\hline \multicolumn{3}{|l|}{ Total comorbidities } \\
\hline 0 & Reference & \multirow[t]{6}{*}{.0775} \\
\hline I & $0.532(0.32-0.884)$ & \\
\hline 2 & $0.505(0.274-0.931)$ & \\
\hline 3 & $0.514(0.256-1.03)$ & \\
\hline 4 & $0.401(0.176-0.911)$ & \\
\hline $5+$ & $0.448(0.142-1.414)$ & \\
\hline Psoriasis impact & I.I82 (I.095-I.275) & $<.0001$ \\
\hline
\end{tabular}

Abbreviation: BSA, body surface area. of respondents reporting moderate-to-severe psoriasis identified counties with statistically significant clustering with $90 \%$ CIs in the southeastern region of the United States (Figure 2B). Gating the input population to BSA $\geq 5 \%$ identified additional counties in Texas and Florida and raised the CIs to $95 \%$ of many of the previously identified counties in Tennessee, North Carolina, South Carolina, Alabama, and Georgia (Figure 2C). Similarly, counties with clustering of biologic use for the treatment of moderate to severe psoriasis were identified in Texas, Ohio, and Michigan with $90 \%$ and $95 \%$ CIs (Figure 2D).

\section{Discussion}

The treatment of psoriatic disease continues to evolve. Here we specifically investigate biologic use among respondents to the 2016 and 2017 NPF Annual Surveys and assess satisfaction with treatment. The NPF Annual Survey aims to assess multiple variables from patients with moderate-to-severe psoriasis.

We show that despite the increasing numbers of biologic therapies approved for the treatment of moderate-to-severe psoriasis, the use was low (22.7\%), opposing our initial hypothesis. Nearly $69 \%$ of respondents reported psoriasis severity as BSA $\geq 3 \%$, indicating that undertreatment remains a concern in an era of treatment targets. ${ }^{2}$ Further, the mild-to-moderate disease severity group, those with $\mathrm{BSA}<3 \%$ and $3 \%$ to $4 \%$, were less likely to receive biologics compared to those with no or very little psoriasis, highlighting an important patient demographic not receiving targeted therapy. The treatment of psoriasis has been pragmatically based on severity and therefore may prohibit the use of biologics in individuals with more mild disease.

Respondents were more satisfied with treatment when their skin was clearer and were being treated with biologic therapy, confirming our second hypothesis. Consistent with our results,

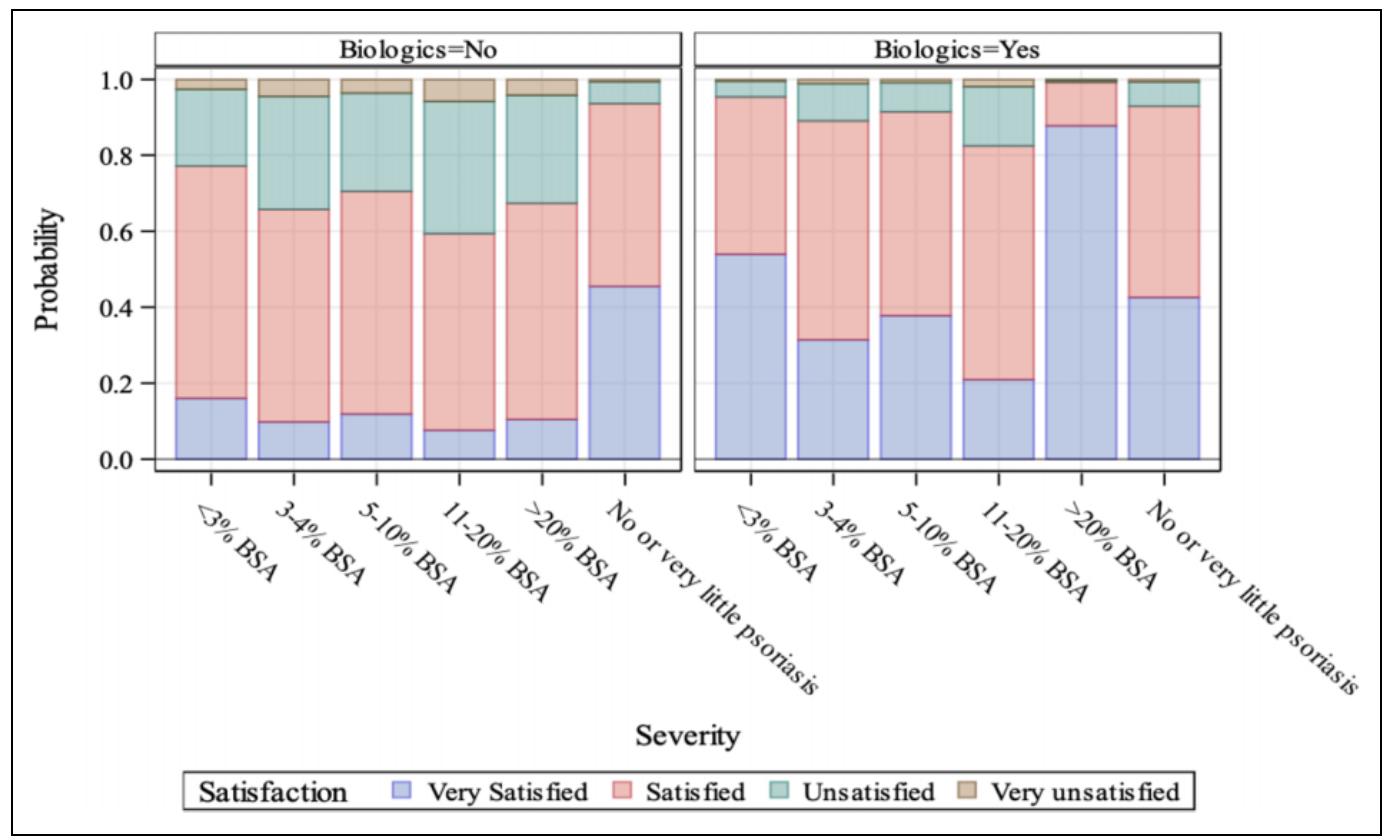

Figure I. Predicted probabilities for satisfaction. Predicted probabilities for satisfaction based on body surface area of psoriasis for those treated with biologic and those not treated with biologic $(P=.040 \mathrm{I})$. 

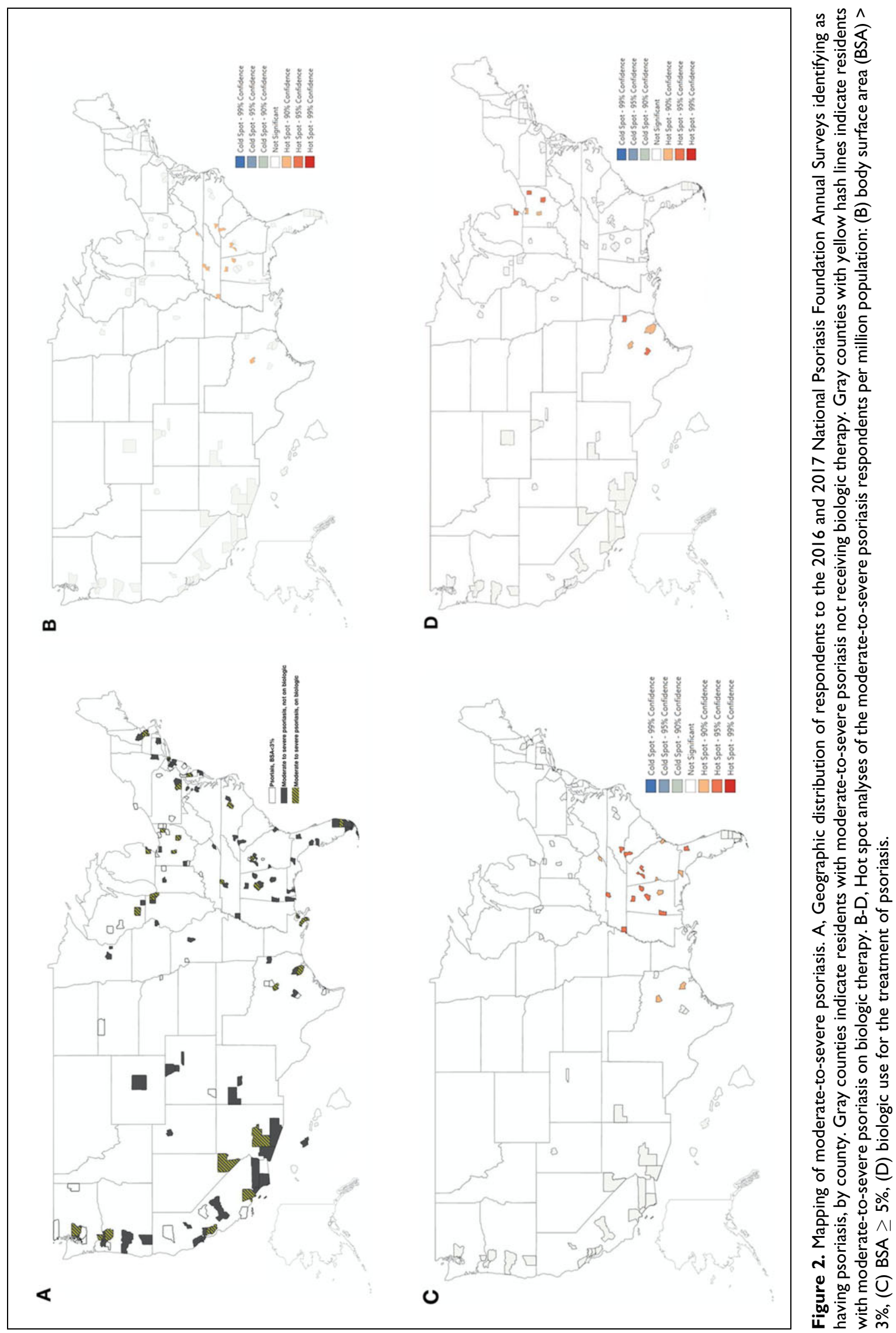
biologic treatment results in higher satisfaction scores when compared to nonbiologic treatments $(P<.001) .{ }^{7}$ Biologic use lowers Dermatology Life Quality Index scores more than other treatment modalities $^{8}$; similarly, more severe disease has a negative emotional and social impact on individuals with psoriasis. ${ }^{9}$ Concordant with these, we showed that a greater impact of psoriasis on a respondent's daily life was predictive of being very unsatisfied with treatment.

Given the discordance between the low frequency of biologic use despite increased patient satisfaction and less severe disease while on these medications, we also considered differences in geographic location as having an impact on biologic use. Step therapy is a policy developed by insurers that dictates treatment choices to control costs. Given the high cost of biologic agents, these treatments may not be initially available to a patient. It was of interest to see if states with Step therapy legislation might have increased use of biologic agents. Similarly, under the Affordable Care Act, Medicaid expansion increased eligibility of many individuals to obtain health insurance; how this impacts access to biologic therapy for psoriasis was not known. Neither Medicaid expansion nor Step therapy legislation associated with biologic use, opposing our third hypothesis. Of note, the timeline from the legislative changes to the timing of the survey was short and should be considered an area for future research.

Spatial variables (ie, residence in proximity to an NPF Medical Board member, US census divisions and regions) did not predict biologic use. However, using GIS we were able to visualize that geographic areas with denser populations, commonly where NPF medical board members reside, were associated with biologic use in our unadjusted model (Supplemental Figure 1). GIS has multiple applications of interest and has previously been used for assessing trends in medication use and identifying geographic areas of disease burden. ${ }^{10-14}$ We were able to identify geographic areas (ie, counties in Kentucky, Tennessee, North Carolina, South Carolina, Georgia, Alabama, Florida, and Texas) where statistically significant clusters of moderate-to-severe psoriasis exist. Importantly, a commensurate hot spot of biologic use was not identified in the majority of these areas. When visualizing the total responses to the NPF 2016 and 2017 Annual Surveys with GIS, there did not appear to be a lack of outreach in those areas (Supplemental Figure 2). Reasons for these areas of clustering will be an area of future research.

There were limitations to this study, primarily its sample size and the response rate to the annual surveys (2016: 1.4\%; 2017: 0.09\%). Arguably, with more data, more granular detail could be used for the GIS analysis. With more data, the hot spot analyses could potentially identify more counties, allowing for further downstream investigations to understand local attributes of those populations that might impact therapy and outcomes. Further, with more data, our chosen geographic variables may have retained or become significant in our analyses. The entire data set is patient reported and is subject to response bias. Further, this database represents only those actively engaged with the NPF, of whom predominantly have moderate-to-severe disease. It is possible that those well controlled on biologic therapy are underrepresented in the survey results. We also do not specify between the classes of biologics and focus on biologics as a broad treatment category. The variance in specific biologic therapy has been studied in select populations ${ }^{15,16}$ and will be an evolving topic for further investigation. Another limitation is that $84 \%$ of respondents identified as Caucasian; this therefore may overrepresent this ethnic group in our various analyses.

\section{Conclusion}

Here, in an analysis of the 2016 and 2017 NPF Annual Surveys, despite increases in the number of biologic therapies, the percentage of patients with psoriasis on biologic therapy remains small $(<23 \%$ ). Roughly $69 \%$ of respondents reported a BSA $\geq 3 \%$, indicating undertreatment remains a concern in the United States. Respondents with mild-to-moderate disease were less likely to receive biologic therapy. Biologic use resulted in greater satisfaction and less residual disease. Geographic variation in state legislation as well as state and federal health insurance did not impact biologic use. However, we identify a greater burden of moderate-to-severe psoriasis among respondents in the Southeastern United States and a lack of commensurate use of biologics in those areas.

\section{Authors' Note}

Data provided by the National Psoriasis Foundation. IRB approval status: Approved (18-03-NH-0069-EVMS).

\section{Acknowledgments}

The authors thank Lindsey Shankle for her assistance with acquiring the data from the 2016 and 2017 National Psoriasis Foundation Annual Surveys.

\section{Declaration of Conflicting Interests}

The author(s) declared the following potential conflicts of interest with respect to the research, authorship, and/or publication of this article. Stacie Bell is current employee of the National Psoriasis Foundation. Dr. Van Voorhees has served as a consultant/consultant to the following companies: Dermira, Novartis, Allergan, Celgene, AbbVie, DermTech, Valeant, WebMD, Pfizer, Astra Zeneca, Merck, Lilly, UCB. She has served as an investigator for the following companies: Celgene, Lilly, AbbVie. Abby S. Van Voorhees is an investigator in Celgene.

\section{Funding}

The author(s) disclosed receipt of the following financial support for the research, authorship, and/or publication of this article: Supported in part by an Alpha Omega Alpha Postgraduate Award.

\section{ORCID iD}

Clinton W. Enos, MD (D) https://orcid.org/0000-0002-6783-1904

Hadiza Galadima, PhD (D) https://orcid.org/0000-0003-1588-3929

Arjun D. Saini, MD (D) https://orcid.org/0000-0002-0756-0743 


\section{Supplemental Material}

Supplemental material for this article is available online.

\section{References}

1. Rachakonda TD, Schupp CW, Armstrong AW. Psoriasis prevalence among adults in the United States. $J$ Am Acad Dermatol. 2014;70(3):512-516.

2. Armstrong AW, Siegel MP, Bagel J, et al. From the Medical Board of the National Psoriasis Foundation: treatment targets for plaque psoriasis. J Am Acad Dermatol. 2017;76(2): 290-298.

3. Menter A, Strober BE, Kaplan DH, et al. Joint AAD-NPF guidelines of care for the management and treatment of psoriasis with biologics. J Am Acad Dermatol. 2019;80(4): 1029-1072.

4. Armstrong AW, Robertson AD, Wu J, Schupp C, Lebwohl MG. Undertreatment, treatment trends, and treatment dissatisfaction among patients with psoriasis and psoriatic arthritis in the United States: findings from the National Psoriasis Foundation surveys, 2003-2011. JAMA Dermatol. 2013;149(10):1180-1185.

5. Status of State Action on the Medicaid Expansion Decision. 2018. https://www.kff.org/medicaid/issue-brief/status-of-state-medi caid-expansion-decisions-interactive-map/ Accessed August 07, 2018.

6. STEP Therapy. [website] 2018: http://www.steptherapy.com/ step-therapy-legislation-by-state/ Accessed May 25, 2018.

7. Ighani A, Yu AM, Sandhu VK, Barankin B, Manolson MF. Satisfaction and awareness of systemic psoriasis treatments: a national survey comparing biologic and nonbiologic users. J Cutan Med Surg. 2019;23(2):148-156.
8. Prado G, Nichols A, Florez-White M, Kerdel F. Quality of life in plaque psoriasis patients treated with biologics: a systematic review. J Am Acad Dermatol. 2018;79(3):236.

9. Krueger G, Koo J, Lebwohl M, Menter A, Stern RS, Rolstad T. The impact of psoriasis on quality of life: results of a 1998 National Psoriasis Foundation Patient-Membership Survey. JAMA Dermatol. 2001;137(3):280-284.

10. Arnlind MH, Wettermark B, Nokela M, Hjemdahl P, Rehnberg C, Jonsson EW. Regional variation and adherence to guidelines for drug treatment of asthma. Eur J Clin Pharmacol. 2010;66(2): 187-198.

11. Cheng CL, Chen YC, Liu TM, Yang YH. Using spatial analysis to demonstrate the heterogeneity of the cardiovascular drugprescribing pattern in Taiwan. BMC Public Health. 2011;11:380.

12. Harvey VM, Enos CW, Chen JT, Galadima H, Eschbach K. The role of neighborhood characteristics in late stage melanoma diagnosis among Hispanic men in California, Texas, and Florida, 1996-2012. J Cancer Epidemiol. 2017;2017:8418904.

13. Tan SY, Buzney E, Mostaghimi A. Trends in phototherapy utilization among Medicare beneficiaries in the United States, 2000 to 2015. J Am Acad Dermatol. 2018;79(4):672-679.

14. Barbieri JS, Etzkorn JR, Margolis DJ. Use of antibiotics for dermatologic procedures from 2008 to 2016. JAMA Dermatol. 2019; 155(4):465-470.

15. Galli E, Liu G, Leslie D, Kirby J, Miller JJ. Prescription pattern variability of biologic therapies in treating psoriasis. $J$ Psoriasis Psoriatic Arthritis. 2018;3(3):84-87.

16. Strober B, Karki C, Mason M. Characterization of disease burden, comorbidities, and treatment use in a large, US-based cohort: results from the Corrona Psoriasis Registry. J Am Acad Dermatol. 2018. 78(2):323-332. 